\title{
Smoking and asthma in adults
}

\author{
R. Piipari*, J.J.K. Jaakkola\#, , N. Jaakkola", M.S. Jaakkola",*
}

Smoking and asthma in adults. R. Piipari, J.J.K. Jaakkola, N. Jaakkola, M.S. Jaakkola. C ERS Journals Ltd 2004.

ABSTRACT: Studies on the effect of smoking on adulthood asthma have provided contradictory results. The current authors conducted a population-based incident casecontrol study to assess the effects of current and past smoking on the development of asthma in adults.

During a 2.5 yr study period, all new asthma cases clinically diagnosed $(n=521)$ and randomly selected controls $(n=932)$ from a geographically defined district in southern Finland were recruited.

The risk of developing asthma was significantly higher among current smokers with an adjusted odds ratio (OR) of $1.33(95 \%$ confidence interval $1.00-1.77)$ and among ex-smokers with an adjusted OR 1.49 (1.12-1.97) compared with never-smokers. Among current smokers, the risk increased up to 14 cigarettes $\cdot$ day $^{-1}$, and a similar trend was observed in relation to cumulative smoking.

In conclusion, the current results support the hypothesis that smoking causes asthma in adulthood.

Eur Respir J 2004; 24: 734-739.
*Finnish Institute of Occupational Health, and "Environmental Epidemiology Unit, Dept of Public Health, University of Helsinki, Helsinki, Finland. "\#Institute of Occupational and Environmental Medicine, University of Birmingham, Birmingham, UK

Correspondence: M.S. Jaakkola, Institute of Occupational and Environmental Medicine, University of Birmingham, Edgbaston, Birmingham, B15 2TT, UK.

Fax: 441214146028

E-mail: M.Jaakkola@bham.ac.uk

Keywords: Asthma, case-control study, smoking

Received: October 202003

Accepted after revision: June 12004

This study was supported by grants from the Finnish Ministry of Social Affairs and Health and the Finnish Work Environment Fund.
Smoking is a major risk factor for morbidity and mortality worldwide. It causes many chronic diseases, including coronary heart disease and chronic obstructive pulmonary disease (COPD). Tobacco smoke is a mixture of $>4,000$ different compounds, many of which are carcinogenic or irritative [1]. The proportion of smokers is still increasing in many developing and developed countries, especially among females [2, 3]. Asthma is one the most common chronic diseases in working-age populations. The prevalence of asthma continues to increase in western countries, and the reasons for this trend are unclear $[4,5]$. Changes in lifestyle, environmental conditions, diagnostic practices and the treatment of asthma may be responsible for this increase [6]. Previous studies on smoking and asthma have provided contradictory results. In many cross-sectional studies, the risk of asthma was not elevated in active smokers compared with never-smokers [7-12], whereas other studies detected an increased risk of asthma in smokers [13, 14]. The few longitudinal studies published have reported inconsistent results on current smoking and asthma [15-19].

The objectives of the current study were to assess the effects of current and past smoking on the development of asthma in a working-age population, and to evaluate parental atopy and sex as potential determinants of susceptibility.

\section{Methods}

\section{Study design}

This study was a population-based incident case-control study. The source population consisted of adults aged

For editorial comments see page 720.
21-63 yrs, living in the Pirkanmaa Hospital District in southern Finland, with a population of 440,913 inhabitants in 1997. Our goal was to recruit all of the new cases of asthma in the source population during the study period. Controls were selected randomly from the source population based on the 1997 population census. The study was approved by the ethics committees of the Finnish Institute of Occupational Health, Helsinki, and the Tampere University Hospital, Tampere, Finland.

\section{Definition and selection of cases}

All of the new cases of asthma were systematically recruited, first, from the city of Tampere from September 15 1997, and, then, from the whole Pirkanmaa Hospital District from March 10 1998-March 31 2000. Patients were recruited by physicians at all healthcare facilities diagnosing asthma, including the Dept of Pulmonary Medicine at the Tampere University Hospital, offices of privately practicing physicians and public healthcare centres. As an additional route of case selection, the National Social Insurance Institution of Finland invited all patients whose reimbursement rights for asthma medication began during the period September 1 1997-May 1 1999 and who had not yet participated.

The diagnostic criteria of asthma included the presence of at least one asthmatic symptom and the demonstration of reversible airway obstruction in lung function investigations, in accordance with the national consensus on the criteria for the diagnosis of asthma (table 1) [20]. All of the confirmed cases of asthma that fulfilled the general eligibility criteria were selected as cases. A total of 521 cases participated: 362 through the healthcare system (response rate 90\%) and 159 through the National Social Insurance Institution (response rate $78 \%$ ). 
History of at least one asthma-like symptom: prolonged cough, wheezing, attacks of or exercise-induced dyspnoea, or nocturnal cough or wheezing and

Demonstration of reversibility in airway obstruction in lung function tests: significant improvement in response to short-acting bronchodilating medication in a bronchodilator test (the criteria for significant changes were: FEV1 $\geqslant 15 \%, \mathrm{FVC} \geqslant 15 \%$, and $\mathrm{PEF} \geqslant 23 \%$ ) and/or $\geqslant 20 \%$ daily variation ${ }^{\#}$ and/or $\geqslant 15 \%$ improvement ${ }^{\#}$ in response to short-acting bronchodilating medication during $\geqslant 2$ days in a 2-week diurnal PEF follow-up and/or significant improvement in spirometric lung function and/or $\geqslant 20 \%$ improvement in the average $\mathrm{PEF}$ level in response to a 2-week oral steroid treatment

FEV1: forced expiratory volume in one second; FVC: forced vital capacity; PEF: peak expiratory flow. ${ }^{\#}$ : calculated according to the standard practice of the Tampere University Hospital [20]; maximum daily variation=(highest PEF value during the day - lowest PEF value during the day)/ highest PEF value during the day; bronchodilator response=(highest PEF value after bronchodilating medication - highest PEF value before medication)/highest PEF value before medication. Data taken from [20].

\section{Selection of controls}

The controls were randomly selected from the source population using the national population registry, which has full coverage of the population. The general eligibility criteria were applied for controls (aged 21-63 yrs, living in the Pirkanmaa Hospital District). After up to three invitation letters and telephone calls, 1,016 controls participated in the study (response rate $80 \%$ of those who had a telephone number in the Pirkanmaa area). After excluding persons reporting previous or current asthma $(n=76)$, persons aged $>63$ yrs $(n=6)$ and those with an incomplete questionnaire $(n=2)$, the current study population included 932 controls.

\section{Smoking information}

Information on smoking was collected with a selfadministered questionnaire inquiring about current and past smoking, smoking rate, and duration and quitting of smoking. The following questions were posed: Do you smoke currently? (yes, regularly; yes, occasionally; no, I quit $<12$ months ago; no, I quit >12 months ago; no, I never smoked regularly); How many years have you smoked?; How much do you/did you smoke on average? (cigarettes, cigars and pipefuls per day, or per week for occasional smokers).

\section{Data collection}

At the Tampere University Hospital, cases were recruited at their first visit because of suspected asthma, and the diagnosis was then verified in clinical examinations. At the other healthcare facilities, cases were recruited immediately after the asthma diagnosis was verified. The same protocol for diagnosing asthma was applied at all healthcare facilities. The National Social Insurance Institution invited the cases to participate $0.5-2$ yrs after their diagnosis was established. For these patients, the criteria of asthma diagnosis and its date were confirmed from their medical records, and the same diagnostic criteria were applied as for the other study patients. All subjects with a previous diagnosis of asthma or long-term use of asthma medication earlier in life were excluded. Eligible subjects were invited to participate in the study and their informed consent was requested by their physician or by letter sent via the National Social Insurance Institution. The recruitment of controls took place at regular intervals throughout the study period. A form for stating their informed consent was sent in the invitation letter and returned in a prepaid envelope to the research nurse of the study project.

\section{Measurement methods}

Questionnaire. The self-administered questionnaire, modified from the Helsinki Office Environment Study questionnaire $[21,22]$ to be used in a general population, included the following six sections: 1) personal characteristics; 2) health information; 3) active smoking and environmental tobacco smoke (ETS) exposure; 4) occupation and work environment; 5) home environment; and 6) dietary habits.

Lung function measurements. The same diagnostic protocol was applied to all patients with suspected asthma [20]. For patients recruited through the National Social Insurance Institution, the data were obtained by abstracting from the medical records. Spirometry accompanied by a bronchodilation test, a 2-week diurnal peak expiratory flow (PEF) follow-up, as well as a 2-week oral steroid treatment test if the other diagnostic tests were negative, were carried out. Interpretation of the lung function results is described in table 1 .

\section{Statistical methods}

Exposure odds ratio (OR) was used to quantify the relationship between exposure and outcome. Adjusted OR was estimated in logistic regression analysis. Sex, age, parental atopy or asthma, education (as an indicator of socioeconomic status), dampness and mould problems in the home or at work, exposure to ETS, any history of pets in the home, and selfreported occupational exposure to sensitisers, dusts or fumes were used as covariates to adjust for potential confounding.

Three parameters of smoking were used, as follows: current smoking status (never-, ex- and current smoker); smoking rate (occasional, 1-14 cigarettes $\cdot$ day $^{-1}, \geqslant 15$ cigarettes $\cdot$ day $^{-1}$ ) and cumulative smoking expressed as cigarette-yrs (average smoking rate $\times$ duration of smoking). The reference category was always never-smoking.

The independent and joint effects of parental atopic diseases and smoking were also studied by comparing the risk of asthma in four exposure categories, as follows: 1) no parental atopy and never-smoking (reference category); 2) parental atopy and never-smoking; 3) no parental atopy and smoking (current, quit smoking $>12$ months ago); and 4) parental atopy and smoking (current, quit smoking $>12$ months ago). ORs were calculated contrasting each of the three exposure categories to the reference category. Estimates for the independent effects of parental atopy, smoking and their joint effect were derived from the same logistic regression model adjusting for the covariates. An analogous approach was applied for studying the effects of sex and smoking, with never-smoking males forming the reference category. 


\section{Results}

\section{Characteristics and smoking among cases and controls}

There were more females among the cases than the controls, and the cases were younger, had more allergic relatives, and were less educated than the controls (table 2). The distribution of smoking habits, smoking rate and cumulative cigarette-yrs among cases and controls are presented in table 3. There were more current and ex-smokers and fewer never-smokers among cases than controls.

\section{Risk of asthma in relation to smoking}

The risk of asthma was significantly related to both former and current smoking, the risk being stronger in ex-smokers (table 3). Considering the smoking rate, the risk of asthma increased from occasional smoking to smoking 1-14 cigarettes $\cdot$ day $^{-1}$, but was lower in the highest smoking category $\left(\geqslant 15\right.$ cigarettes $\cdot$ day $\left.^{-1}\right)$. An increased risk of asthma was also observed among those with lifetime smoking of 1-199 cigarette-yrs, but a slightly lower risk was observed in the highest cumulative smoking category $(\geqslant 200$ cigarette-yrs). Similar trends according to the amount of smoking were detected in both males and females.

Table 2. - Characteristics of the study population, The Finnish Environment and Asthma Study 1997-2000

\begin{tabular}{|c|c|c|}
\hline Characteristics & Cases & Controls \\
\hline Total n & 521 & 932 \\
\hline \multicolumn{3}{|l|}{ Sex } \\
\hline Male & $175(33.6)$ & $438(47.0)$ \\
\hline Female & $346(66.4)$ & $494(53.0)$ \\
\hline \multicolumn{3}{|l|}{ Age yrs } \\
\hline $21-29$ & $108(20.7)$ & $141(15.1)$ \\
\hline $30-39$ & $107(20.5)$ & $224(24.0)$ \\
\hline $40-49$ & $125(24.0)$ & $254(27.3)$ \\
\hline $50-59$ & $140(26.9)$ & $240(25.8)$ \\
\hline $60-63$ & $41(7.9)$ & $73(7.8)$ \\
\hline \multicolumn{3}{|l|}{ Parental allergic diseases } \\
\hline Maternal allergy & $85(16.3)$ & 108 (11.6) \\
\hline Paternal allergy & $47(9.0)$ & $48(5.2)$ \\
\hline Maternal asthma & $66(12.7)$ & $64(6.9)$ \\
\hline Paternal asthma & $62(11.9)$ & $48(5.2)$ \\
\hline Any & $186(35.7)$ & $204(21.9)$ \\
\hline \multicolumn{3}{|l|}{ Education $^{\#}$} \\
\hline No vocational schooling & $107(20.6)$ & $154(16.6)$ \\
\hline Vocational course & $89(17.2)$ & $104(11.2)$ \\
\hline Vocational institution & $149(28.7)$ & $271(29.2)$ \\
\hline College-level education & $113(21.8)$ & $261(28.1)$ \\
\hline University or corresponding & $61(11.8)$ & $138(14.9)$ \\
\hline \multicolumn{3}{|l|}{ ETS } \\
\hline At work & $89(17.1)$ & $130(13.9)$ \\
\hline At home & $30(5.9)$ & $52(5.6)$ \\
\hline \multicolumn{3}{|l|}{ Pets at home } \\
\hline Never & $134(25.7)$ & $269(28.9)$ \\
\hline Currently & $222(42.7)$ & $420(45.1)$ \\
\hline$>12$ months ago & $165(31.7)$ & $243(26.1)$ \\
\hline Sometimes & 387 (74.3) & $663(71.1)$ \\
\hline $\begin{array}{l}\text { Indoor mould exposure at work or } \\
\text { at home }\end{array}$ & $123(23.8)$ & $192(20.7)$ \\
\hline Any work exposure & $313(60.1)$ & $579(62.1)$ \\
\hline
\end{tabular}

Data are presented as $\mathrm{n}$ and $\mathrm{n}(\%)$. ETS: environmental tobacco smoke. \#: data missing for six subjects; ": self-reported exposure to sensitisers, dusts and/or fumes.
Parental atopy and sex as potential determinants of susceptibility

Table 4 presents the estimated independent and joint effects of parental atopy and smoking (both current and exsmoking). The adjusted ORs in population-based incident case-control studies represent estimates of incidence rate ratios [23]. Using a common reference category, the magnitude of independent and joint effects can be compared. In this study, the common reference category was never-smokers without a history of parental atopy. The independent excess risk $(95 \%$ confidence interval (CI)) of asthma related to

Table 3. - Distribution of smoking in cases and controls, and adjusted odds ratio (OR) of asthma in relation to smoking, The Finnish Environment and Asthma Study 1997-2000

\begin{tabular}{lccc}
\hline & Cases & Controls & OR $^{\#}(95 \%$ CI $)$ \\
\hline $\begin{array}{l}\text { Total n } \\
\text { Smoking }\end{array}$ & 518 & 930 & \\
$\quad$ Never-smoker & $239(46.1)$ & $487(52.4)$ & 1.00 \\
Ex-smoker & $133(25.7)$ & $203(21.8)$ & $1.49(1.12-1.97)$ \\
$\quad$ Current & $146(28.2)$ & $240(25.8)$ & $1.33(1.00-1.77)$ \\
Smoking rate $^{+}$ & & & \\
$\quad$ cigarettes·day & & & \\
$\quad$ Never-smoker & $239(46.1)$ & $487(52.4)$ & 1.00 \\
Ex-smoker & $133(25.7)$ & $203(21.8)$ & $1.46(1.10-1.95)$ \\
Occasional & $31(6.0)$ & $50(5.4)$ & $1.25(0.76-2.06)$ \\
$\quad 1-14$ & $55(10.6)$ & $59(6.3)$ & $1.93(1.26-2.95)$ \\
$\geqslant 15$ & $57(11.0)$ & $122(13.1)$ & $1.05(0.71-1.56)$ \\
Cumulative smoking & & & \\
$\quad$ cigarette-years & & & \\
Never-smoker & $239(46.1)$ & $487(52.4)$ & 1.00 \\
Ex-smoker & $133(25.7)$ & $203(21.8)$ & $1.47(1.11-1.96)$ \\
Occasional & $31(6.0)$ & $50(5.4)$ & $1.25(0.76-2.06)$ \\
$1-199$ & $37(7.1)$ & $53(6.0)$ & $1.46(0.90-2.37)$ \\
$\geqslant 200$ & $73(14.1)$ & $127(13.7)$ & $1.31(0.91-1.89)$ \\
\hline
\end{tabular}

Data are presented as $\mathrm{n}$ and $\mathrm{n}(\%)$, unless otherwise stated. CI: confidence interval. \#: adjusted for sex, age, parental atopy/asthma, education, environmental tobacco smoke at home or at work, dampness and mould problems at home or at work, self-reported occupational exposures and pets; ${ }^{\uparrow}$ : data missing for three cases and two controls; ${ }^{+}$: data missing for three cases and nine controls; \$: data regarding cigarette-years among daily smokers was missing for five cases and 10 controls.

Table 4. - Independent and joint effects of parental atopy and cigarette smoking on the risk of asthma, The Finnish Environment and Asthma Study 1997-2000

Adjusted $^{\#}$ OR (95\% CI) Risk increase \%

No parental atopy and

1.00 never-smoking

Parental atopy and never-smoking

No parental atopy and current smoking

No parental atopy and ex-smoking

Parental atopy and current smoking

Parental atopy and ex-smoking

$\begin{array}{lr}2.15(1.52-3.06) & 115 \\ 1.43(1.02-1.99) & 43 \\ 1.60(1.14-2.24) & 60 \\ 2.43(1.52-3.90) & 143 \\ 2.70(1.70-4.27) & 170\end{array}$

OR: odds ratio; CI: confidence interval. \#: adjusted for sex, age, education, environmental tobacco smoke at home or at work, dampness and mould problems at home or at work, self-reported occupational exposures and pets; ${ }^{\uparrow}$ : reference category. 
Table 5. - Independent and joint effects of sex and cigarette smoking on the risk of asthma, The Finnish Environment and Asthma Study 1997-2000

Adjusted $^{\#}$ OR $\quad$ Risk increase \%
$(95 \% \mathrm{CI})$

\begin{tabular}{lcr}
\hline Male and never-smoking & 1.00 & \\
Female and never-smoking & $1.57(1.09-2.27)$ & 57 \\
Male and current smoking & $1.04(0.66-1.65)$ & 4 \\
Male and ex-smoking & $1.34(0.86-2.09)$ & 34 \\
Female and current smoking & $2.43(1.56-3.79)$ & 143 \\
Female and ex-smoking & $2.38(1.51-3.76)$ & 138
\end{tabular}

OR: odds ratio; CI: confidence interval. ${ }^{*}$ : adjusted for age, parental atopy, education, environmental tobacco smoke at home or at work, dampness and mould problems at home or at work, self-reported occupational exposures and pets; ": reference category.

parental atopy was estimated to be $115 \%(52-206)$, i.e. 2.15 incidence rate ratio between parental atopy/never-smoking and the reference category. Similarly, the independent effects of current and former smoking were 43\% (2-99) and $60 \%$ (14-124), respectively. The joint effect of parental atopy and current smoking was estimated to be 143\% (52-290), which was close to what was expected on the basis of independent effects on an additive scale $(115+43=158 \%)$. Also, the estimated joint effect of parental atopy and former smoking, $170 \%$, corresponded to the sum of independent effects $(115+60=165 \%)$.

Table 5 illustrates the independent and joint effects of sex and smoking, using never-smoking males as the reference category. In never-smoking subjects, the female sex was related to a significantly increased risk of asthma, with an adjusted OR (95\% CI) of 1.57 (1.09-2.27), corresponding to a $57 \%$ excess risk. The association between current smoking and asthma was not significant in males (1.04 (0.66-1.65)). The risk of asthma increased slightly in relation to exsmoking in males (1.34 (0.86-2.09)). In a separate analysis including females only, the risk of asthma increased significantly in relation to both current smoking (1.62 (1.13-2.34)) and ex-smoking (1.52 (1.04-2.23); data not shown). The joint effect of female sex and current smoking (table 5) resulted in a $143 \%$ increase in the risk of asthma (OR 2.43) compared to never-smoking males. The combined effect of sex and smoking would be $61 \%$ on the basis of their independent effects $(57 \%$ for female sex $+4 \%$ for current smoking); this means that there was an interaction of $82 \%$ on an additive scale $(143-61=82 \%)$. There was also an interaction of $47 \%$ for the effects of female sex and ex-smoking (joint effect $138 \%$ - (expected effects $57 \%$ for female sex $+34 \%$ for ex-smoking $=47 \%$ ).

\section{Discussion}

This is the first incident case-control study in which the associations between new adult asthma and both cumulative lifetime and recent smoking have been investigated. From an incident case-control study, the cause-effect relationship can be assessed, and even more so when cumulative exposure is taken into account. The results show an increased risk of asthma in former and current smokers, the effect being stronger in former smokers. Among current smokers, the risk of asthma increased from occasional to moderate smokers, but decreased in heavy smokers. A similar trend was detected in relation to cumulative lifetime smoking. These trends may be explained by behavioural changes that smokers undertake because of respiratory symptoms, even before asthma is diagnosed. The current results suggest that smokers who are prone to develop asthma either stop smoking because of respiratory symptoms before the diagnosis is made, or continue to smoke at a moderate rate because of their respiratory symptoms.

Some individuals seemed to be less susceptible to the effects of tobacco smoke and smoked heavily without getting asthma. This points to genetic or other susceptibility factors rendering individuals to be differently sensitive to the harmful effects of tobacco smoke. Such a selection phenomenon may explain some of the discrepancies in the results of previous studies, especially of those with a cross-sectional study design.

There are many potential mechanisms by which smoking may jeopardise the smoker to asthma. Cigarette smoke causes airway inflammation, increases airway epithelial permeability, modulates the immune system and impairs normal repair processes [24]. At the individual level, these mechanisms interact with genetic and other environmental factors modifying the individual risk. Heredity to atopy could be a possible susceptibility factor for asthma in smokers. However, it was found that the joint effect of parental atopy and smoking on the risk of asthma was additive rather than synergistic. It is possible that individuals with atopic heredity are less likely to take up smoking. Females were found to be more susceptible to the effects of smoking than males. Nonsmoking females were estimated to have a $57 \%$ excess risk of asthma compared with nonsmoking males. The interaction between sex and smoking was $82 \%$, the risk of asthma being significantly related to active smoking in females, but not in males. In females, the risk estimates for smoking and ex-smoking were similar, whereas, in males, the risk for asthma was slightly associated with ex-smoking. These results could be interpreted so that males are more inclined to quit smoking after the onset of first symptoms and signs, whereas females tend to continue smoking. Whether this indicates a stronger addiction to tobacco among females remains to be studied.

\section{Validity issues}

Our aim was to reach all newly diagnosed asthma cases in a geographically defined area. With the thorough recruitment system, via the healthcare facilities and the help of the National Social Insurance Institution, it is believed that this objective was well achieved. In Finland, the National Social Insurance Institution offers a significant reimbursement for asthma medicines to every asthmatic fulfilling our diagnostic criteria, which means that most, if not all, new asthma cases are reported to the Institution by physicians. As the response rate among cases and controls was good, there is no reason to believe that any major selection bias would exist.

Newly diagnosed asthmatics may either underestimate or overestimate their smoking history because of fears regarding the new disease, but as the study was introduced to the participants as a study on environmental factors in general, and smoking-related questions were only one part of the questionnaire, major recall bias is not likely to have occurred. All asthmatics, apart from those recruited through the National Social Insurance Institution, answered the questions on smoking habits before or at the time when their diagnosis was established. To accurately assess the exposure, both ex- and current smokers were asked about the number of cigarettes smoked per day and the time since quitting, making it possible to quantify lifetime cumulative exposure and to study the dose-response relationship between smoking and asthma.

The difference between COPD and asthma may be difficult to detect when using questionnaire-based diagnosis only, as 
the symptoms of these two conditions overlap. To improve the validity of diagnosis of asthma in the current study, asthma diagnosis was confirmed by lung function measurements showing reversible airway obstruction in spirometry and/or PEF surveillance. As a consequence of this, clear COPD cases were excluded from this study population. Inclusion of COPD cases would lead to overestimation of the risk, since smoking is known to be a strong determinant of COPD [25]. Conversely, self-reporting of asthma might lead to underestimation of the risk, given that smokers might interpret their respiratory symptoms as asthmatic, even though in reality they could be signs of nonobstructive processes. Since all the physicians diagnosing asthma in the current study region agreed to apply a standardised diagnosing protocol, based on the national consensus criteria for the asthma diagnosis [20], good validity in the assessment of asthma was achieved. Cases with an earlier diagnosis of asthma or long-term use of asthma medication ever during lifetime were excluded to confirm that only new cases were included. Previously diagnosed asthma would have diluted the risk estimate, since physicians usually advise asthmatics to quit smoking.

Adult-onset asthma has a multifactorial aetiology; for example, indoor mould problems [26], pets [27], and ETS [28] all increase the risk of asthma. In the multivariate logistic regression analyses, the effects of many important potential confounders, e.g. age, pets, dampness and mould problems, and occupational exposures, were controlled. In no earlier study on the association between smoking and asthma have all these confounders been simultaneously controlled.

\section{Synthesis with previous studies}

This large incident case-control study provides evidence of an increased risk of asthma in current and former smokers, especially in females. Previous studies have provided conflicting results. In two earlier longitudinal studies [17, 18], an increased risk of asthma in smokers compared with never or nonsmokers (including both never- and ex-smokers) was found, in line with the current results. In contrast, in the study by TROISI $e t$ al. [16], the risk of asthma among current smokers was approximately half that of never- and ex-smokers. The risk of asthma was increased among ex-smokers for the first 5 yrs after quitting. In the study by GODTFREDSEN et al. [19], ex-smokers had a higher incidence of self-reported asthma than never-smokers. In the 6-yr follow-up study from Finland [15], asthma risk was not increased in either current or exsmokers compared with never-smokers. Two earlier crosssectional studies have found a greater susceptibility to asthma in females in relation to smoking [29, 30], whereas no sex difference was observed in the Finnish 6-yr follow-up study [15].

In all of these studies, the asthma diagnosis was based on the self-reporting of symptoms, doctor-diagnosed asthma or the use of asthma medication, or hospital admissions due to asthma, making some misclassification of asthma cases likely. In only one previous study were persons with doctordiagnosed chronic bronchitis excluded [16]. Occupational exposures or exposure to ETS were not taken into account, and assessment of smoking history did not include lifetime exposure. Compared with the earlier studies, the strength of the current study lies in the accuracy of the assessment of both exposure and asthma, the critical issues in terms of validity of the results. Our efforts aimed to include only new cases of asthma to reduce the potential effects of selection and recall bias that often affect studies with prevalent cases of asthma.

\section{Conclusions}

The current results are consistent with the hypothesis that smoking causes asthma in adulthood. The stronger effect of former smoking and the nonlinear relationship with the quantity of smoking seem to point to a behavioural change as a response to beginning symptoms. The results suggest that smokers who are prone to develop asthma either stop smoking or continue to smoke at a moderate rate because of their respiratory symptoms. Females seem to be more susceptible to the adverse effects of smoking than males. Whether this is explained by different biological susceptibility to the harmful effects of tobacco smoke, or by females being more addicted to tobacco, needs to be studied further.

\footnotetext{
Acknowledgements. The authors would like to thank the research nurses, L. Yrjänheikki, M. Soukkanen and M. Aalto, as well as the physicians and nurses who participated in recruiting the study subjects at the Tampere University Hospital, healthcare centres and private practices. The National Social Insurance Institution of Finland is thanked for providing the additional route of case recruitment. The authors would also like to thank T. Kaustia for revision of the language.
}

\section{References}

1. Hoffmann D, Hoffmann I. The changing cigarette, 1950-1995. J Toxicol Environ Health 1997; 50: 307-364.

2. Evans A, Tolonen H, Hense HW, Ferrario M, Sans S, Kuulasmaa K. Trends in coronary risk factors in the WHO MONICA project. Int J Epidemiol 2001; 30: Suppl. 1, 35-40.

3. Nelson DE, Bland S, Powell-Griner E, et al. State trends in health risk factors and receipt of clinical preventive services among US adults during the 1990s. JAMA 2002; 287: 2659 2667.

4. Sly MR. Changing prevalence of allergic rhinitis and asthma. Ann Allergy Asthma Immunol 1999; 82: 233-248.

5. Beasley R. The burden of asthma with specific reference to the United States. J Allergy Clin Immunol 2002; 109: Suppl. 5, S482-S489.

6. Magnus P, Jaakkola JJK. Secular trend in the occurrence of asthma among children and young adults: critical appraisal of repeated cross sectional surveys. BMJ 1997; 314: 17951799.

7. Lebowitz MD. Smoking habits and changes in smoking habits as they relate to chronic conditions and respiratory symptoms. Am J Epidemiol 1977; 105: 534-543.

8. Senthilselvan A, Chen Y, Dosman JA. Predictors of asthma and wheezing in adults. Am Rev Respir Dis 1993; 148: 667670.

9. Pilotto LS, Smith BJ, Nitschke M, Ruffin RE, Mitchell R. Industry, air quality, cigarette smoke and rates of respiratory illness in Port Adelaide. Aust N Z J Public Health 1999; 23: 657-660.

10. Walraven GEL, Nyan OA, van der Sande MAB, et al Asthma, smoking and chronic cough in rural and urban adult communities in The Gambia. Clin Exp Allergy 2001; 31: 1679-1685.

11. Hjern A, Hedberg A, Haglund B, Rosen M. Does tobacco smoke prevent atopic disorders? A study of two generations of Swedish residents. Clin Exp Allergy 2001; 31: 908-914.

12. Flodin U, Jonsson P. Non-sensitising air pollution at workplaces and adult onset asthma. Int Arch Occup Environ Health 2003; 77: 17-22.

13. Becker V, Nepper-Christensen S, Ulrik CS, von Linstow ML, Porsbjerg C. Factors associated with asthma in young 
Danish adults. Ann Allergy Asthma Immunol 2002; 89: 148154.

14. Arif AA, Delclos GL, Lee ES, Tortolero SR, Whitehead LW. Prevalence and risk factors of asthma and wheezing among US adults: an analysis of the NHANES III data. Eur Respir $J$ 2003; 21: 827-833.

15. Vesterinen E, Kaprio J, Koskenvuo M. Prospective study of asthma in relation to smoking habits among 14729 adults. Thorax 1988; 43: 534-539.

16. Troisi RJ, Speizer FE, Rosner B, Trichopoulos D, Willett WC. Cigarette smoking and incidence of chronic bronchitis and asthma in women. Chest 1995; 108: 1557-1561.

17. Torén K, Hermansson B-A. Incidence rate of adult-onset asthma in relation to age, sex, atopy and smoking: a Swedish population-based study of 15813 adults. Int J Tuberc Lung Dis 1999; 3: 192-197.

18. Plaschke PP, Janson C, Norrman E, Björnsson E, Ellbjär S, Järvholm B. Onset and remission of allergic rhinitis and asthma and the relationship with atopic sensitization and smoking. Am J Respir Crit Care Med 2000; 162: 920924.

19. Godtfredsen NS, Lange P, Prescott E, Osler M, Vestbo J. Changes in smoking habits and risk of asthma: a longitudinal population based study. Eur Respir J 2001; 18: 549-554.

20. Committee on the National Asthma Programme in Finland. Asthma Programme 1994-2004 (in Finnish). Helsinki, Ministry of Social Affairs and Health, 1994.

21. Jaakkola JJK, Miettinen P. Type of ventilation system in office buildings and sick building syndrome. Am J Epidemiol 1995; 141: 755-765.

22. Jaakkola MS, Jaakkola JJK. Office equipment and supplies: a modern occupational health concern? Am J Epidemiol 1999; 150: 1223-1228.

23. Miettinen OS. Estimability and estimation in case-referent studies. Am J Epidemiol 1976; 103: 226-235.

24. Floreani AA, Rennard SI. The role of cigarette smoke in the pathogenesis of asthma and as a trigger for acute symptoms. Curr Opin Pulm Med 1999; 5: 38-46.

25. US Department of Health and Human Services. The health consequences of smoking: chronic obstructive pulmonary disease. A report of the Surgeon General. Public Health Service, Office of Smoking and Health. DHHS Publication No. 84-50205, 1984.

26. Jaakkola MS, Nordman H, Piipari R, et al. Indoor dampness and molds and development of adult-onset asthma: a population-based incident case-control study. Environ Health Perspect 2002; 110: 543-547.

27. Jaakkola JJK, Jaakkola N, Piipari R, Jaakkola MS. Pets, parental atopy, and asthma in adults. J Allergy Clin Immunol 2002; 109: 784-788.

28. Jaakkola MS, Piipari R, Jaakkola N, Jaakkola JJK. Environmental tobacco smoke and adult-onset asthma: a population-based incident case-control study. Am J Public Health 2003; 93: 2055-2060.

29. Chen Y, Dales R, Krewski D, Breithaupt K. Increased effects of smoking and obesity on asthma among female Canadians: the national population health survey, 1994-1995. Am J Epidemiol 1999; 150: 255-262.

30. Kiviloog J, Irnell L, Eklund G. The prevalence of bronchial asthma and chronic bronchitis in smokers and non-smokers in a representative local Swedish population. Scand J Respir Dis 1974; 55: 262-276. 